\title{
Rancière and Occupy (in) London: An Interview with A.N.Onymous ${ }^{1}$
}

\author{
SAMUEL BURGUM, University of Warwick
}

\section{ABSTRACT}

Based upon an interview with the activist A.N.Onymous that was published on the Theory, Culture \& Society website, this article seeks to indicate some of the ways in which the theory of Jacques Rancière might be useful for a critical and reflective understanding of Occupy (in) London. A.N.ON's insights into the movement and the theory are elaborated throughout using Rancière's concepts in order to suggest some of the ways that they might inform each other, covering such themes as: expertise; authority; horizontality and democracy; the politics of aesthetics; as well as the importance of space in resistance.

\section{KEYWORDS}

Jacques Rancière; Occupy London; Expertise; Authority; Resistance 


\section{Introduction}

A.N.Onymous and I first met at 'Occupation Finsbury Square', Islington, in May 2012 after the eviction of the well-known 'London Stock Exchange' (LSX) encampment at St Paul's Cathedral. At the time, Occupy London were undergoing a decisive split between those at Finsbury (who emphasised the 'settlement' and the importance of urban campsites) and those ex-LSX campers (who now emphasised the 'movement' and the 'occupation of hearts and minds'). As such, 'Occupy LSX' appeared to have become 'Occupy London TM', taking over the 'brand' for their own purposes, whilst the group at Finsbury Square had become sidelined, stigmatised and neglected, seen as 'nothing more' than homeless drug addicts and alcoholics with mental illnesses. To make the division worse, 'Occupy London TM' began to withhold resources and donations from Finsbury, forcing the latter into a situation where they could simply no longer maintain a functioning campsite and creating a bitter resentment between them.

A.N.ON has always been firmly on the 'Finsbury' side of things, emphasising the encampments as the central contribution of Occupy and as crucial to their post-crash resistance. A self-described war artist and conscientious objector to the British government, whenever I have met with A.N.ON over the last few years I have always found him to be a particularly reflective and critical member of the movement. He has an exceptional talent for wordplay, which he uses to continually challenge Occupy to be better and willing to learn from its mistakes, and the fact that he is always dressed in ski-goggles, pillow case headwear and Garfield pyjamas adds an air of mystery and gravitas to his reflections. Furthermore, A.N.ON's lack of melancholia and willingness to be critical is particularly refreshing, offering illuminating and interesting observations of Occupy (in) London in a context where romanticism (particularly in theoretical work) is rife.

As such, when I was approached by the Theory, Culture \& Society website to write something about Occupy for a special edition being published on Jacques Rancière which includes a number of articles on the link between the movement and the theorist (Lorey 2014; Raunig 2014) - I suggested that I might interview A.N.ON to get a different perspective on Rancière's theory and its potential usefulness for 
Occupy. Upon arranging an interview, A.N.ON proceeded to read some Rancière (although rightly pointed out that doing thorough 'homework' would probably not have been very 'Rancièrean') and we met in July 2014 at an environmental protest camp at Cat Hill, North London.

While the resulting blog post (Burgum \& A.N.Onymous 2014) is simply a standalone interview transcript (that we collaboratively edited), what I intend to do in this article is flesh out some of the themes which came out of this discussion. As such, I will work through some of the ideas and comments that A.N.ON made, whilst elaborating some of Rancière's theory, in order to make parallels that are by no means exhaustive of either; but simply indicative of some of the ways we found Rancière's theory to be potentially useful for a critical understanding of Occupy (in) London. As such, this is not intended to be a generalisation of an entire movement on the basis of a single interview, but is instead a modest attempt to indicate some potentially useful crossovers that we found between Occupy (in) London and Rancière's theory. The theoretical discussion below is directed by the themes covered in the interview, rather than by an attempt to make an empirical claim on representing Occupy as a whole.

Indeed, as has been argued elsewhere, any attempt to conduct research with contemporary movements is perhaps necessarily flawed because it creates a distortion of their democratic self-representation through the researcher's representation: in all likelihood, over-emphasising the homogeneity and coherence of a movement at the expense of their actual internal complexity (Prentoulis \& Thomassen 2013). Of course, "the aim is to let the protestors speak for themselves, and to treat their language as the language in which our analysis is cast", yet "this is at once necessary and impossible" (Pretoulis \& Thomassen 2013:169), because as soon as one seeks to represent the protestors, they are no longer speaking for themselves. Therefore, I argue, research should not try and claim to have unconcealed the 'truth' (aletheia) of such movements, but instead seek to be a political reflection upon resistance that is elaborated using theoretical ideas. Furthermore, researchers should take seriously the epistemological stance that activists are also theorists who utilise and reflect on theory as much as the 'activist-academic' expert. This is a vital epistemological and political stance, as well as one which is quite 'Rancièrean', because it undermines the relationship of expert authority (which I take to mean "guidance, judgement or 
witness from the position of "knowing better"' (Blencowe 2013:15) between the researcher and the researched. All we can hope to do, then, is to advocate a position in which the researcher is "working with rather than on participants" (Sinha \& Back 2013:3) (assuming that the term 'participants' still has any relevance here).

This article begins by establishing the context and democratic aims of Occupy, before suggesting that paradoxical 'experts on equality' undermined these aims precisely through their presupposition of authority. By drawing parallels with Rancière's critique of Althusser following May '68, it is suggested that this can be used to reflect on the way in which the same contradictory expertise might have undermined Occupy's aims. The second section then looks at whether Occupy was able to presuppose equality within the movement (a democratic aim that I suggest is shared by Rancière and Occupy alike) yet also seeks to point to the experience within Occupy as highlighting a slight contradiction in Rancière's theory. A.N.ON's observation within the movement was that presupposing equality was not necessarily the same as achieving it in practice, precisely because some were pre-positioned as having illegitimate voice from the start, and were therefore unwilling to 'speak' (indicating a potential contradiction between Rancière's separate theories of presupposing equality and le partage du sensible). In the final section, it is then argued that there is a link to be made between the tactic of occupying space and Rancière's unique theory of power via the policing of aesthetic appearances. This leads us to conclude that not only was the difference between the 'movement' and the 'settlement' the fundamental (and terminal) division within Occupy London, but that the experience of this split can indicate some of the difficulties of putting Rancière's theory into practice. I begin each section with the questions that I asked A.N.ON in order to be clear of the direction of our conversation, before proceeding with a theoretical discussion of the themes that arose.

\section{Was there a problem with unequal power and authority within Occupy London?}

When the Occupy movement began in New York, their intention was to ride the wave of other 2011 movements - such as the Arab Spring and the 'Indignados' of Southern 
Europe - as well as tap into a growing resentment towards the apparent democratic deficit and injustice of bailing out private institutions using public money following the financial crash of 2007/8. In the UK context, a post-political general election in 2010 - in which three white, male, privileged candidates all represented neoliberal austerity - rendered the ballot a reality-TV talent competition for picking the freshest face for the same job (Winlow 2012), and subsequently landed a right-of-centre coalition government. The upshot of this was broken promises towards increasing student tuition fees (from promises of abolition to being tripled); an ideologically motivated attack on public services and welfare institutions (known as the 'cuts' or 'austerity measures'); as well as an increase in a marginalising rhetoric that stigmatised 'shirkers' and 'immigrants' that were supposed to comprise the urban poor (further justifying the kind of institutional racism that sparked and sustained the urban riots in the summer of 2011).

Occupy, therefore, was supposed to represent something that was democratically different against this perceived democratic deficit (or at least the desire and search for

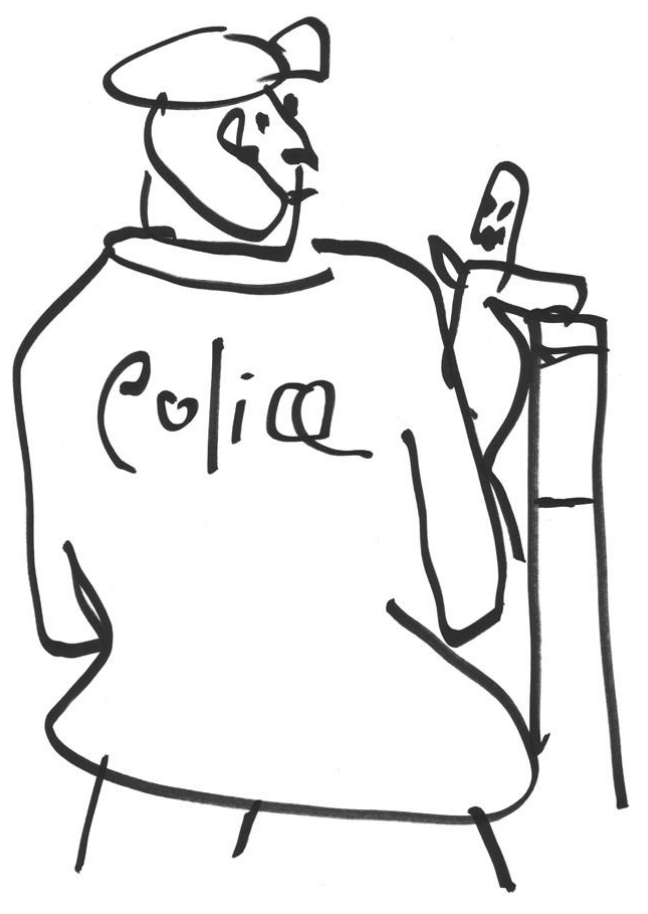
a democratic alternative) and, in London, this took the form of a camp that was set up outside St Paul's cathedral as well as subsequent sites all over the city in various buildings and parks. Although originally intended to be outside the stock exchange on Paternoster Square, the kettling of the protestors outside the cathedral led to some interesting developments: challenging the Church of England to take a stance towards the morally questionable neoliberal reaction to the financial crash and the increasing inequality in society. Juxtaposed to the perceived corruption of the stock exchange, the cathedral and the government, therefore, Occupy (in) London positioned itself as for democracy, equality and social justice, and against a system that appeared to represent a democratic deficit, inequality and social injustice. 
Occupy LSX at St Paul's subsequently borrowed imagery and slogans from the American, European and Arab movements in order to illustrate this position (as well as creating many of its own). These included the now infamous 'We are the 99\%' that began as an online photographic campaign where people held up placards that outlined their debt in an act of solidarity (Tumblr 2014); as well as 'This is what Democracy looks like' (recycled from the Global Justice Movement of the late nineties) and 'Capitalism is Crisis' (re-using a banner that had been first made for the Climate Camp protests that preceded Occupy London). Furthermore, the adoption of the directly democratic 'General Assembly' (GA) model was taken to embody these core values. Adapted from the Quaker consensus model, this included: a series of elaborate hand signals to allow group participation; conventions in who may speak and for how long; methods of decision making that meant everyone present must agree in order for a decision to be made; as well as a controversial 'blocking' system that allowed someone who didn't agree to prevent a decision from being carried. The intention was to allow for a more direct democracy (as opposed to a representational democracy) and a widespread inclusive participation that was supposed to maintain the horizontality of a leaderless space and movement.

Yet, whilst this began in earnest and with some preliminary success, it appears that Occupy's experiment soon became difficult to maintain within the camp environment. Continual media attention meant that, not only did some occupiers become de facto leaders by speaking on behalf of the movement, but also the creation of a continual stress-inducing scrutiny of the actions of those in the camp (for instance, when The Daily Mail (2011) used heat-sensing equipment to see how many tents were actually 'occupied'). Add to this the cold London winter rain and snow; the hard paving slabs; the cathedral bells chiming every 15 minutes; the patrons of the City of London, the local pubs and bars - and even the cathedral - shouting abuse and sometimes turning violent; the lack of food or hygiene; the lack of support for those with alcohol problems, drug addictions, or mental illness... and the patience with the GA model soon began to run out. Frustration began to show and fault-lines began to appear, creating splits and tensions within what was intended to be a space of solidarity and direct democracy. Many of the occupiers decided to set up further sites to alleviate the pressure at St Paul's (including Finsbury Square in Islington), yet some simply no 
longer felt safe within that environment and opted to leave or turn to other activities that did not require their physical presence in camps.

Subsequently, as A.N.ON argues, there was a problem with unequal power and authority within the movement that contradicted the initial horizontal democratic intentions and values that Occupy was supposed to stand for. It seemed that the movement had not managed to maintain the egalitarian space that it had set out to be, and non-official 'leaders' had inadvertently come about. What's more, these leaders often appeared to have increased capital due to their status as being 'original' members of the camps, and through possessing specialist knowledge of democratic or resistive processes:

There was a 'tyranny of the founders', a sort of inner circle that were 'experts' in activism teaching us 'how it's done'. I suppose if I was an expert of activism in London - and I'd been around and I'd earned my spurs and my 'credit rating' was high - then I could probably meet these people and they could vet me. But one phrase that appeared at the end was 'the circle of trust' and it became an identity thing: 'them and us'.

Therefore, against claims that Occupy was able to maintain an 'interstitial space' and 'prefigure' democratic alternatives (Bassett 2014:5-6), A.N.ON's experience suggests that those Occupiers who self-identified as 'experts' on how to prefigure democracy (for instance, how to run a GA or how to maintain a horizontal camp) had, in fact, adopted positions of power that paradoxically undermined the legitimacy of the democracy they were supposed to be enacting. In other words, as A.N.ON puts it: 'you can tell who the hierarchy are because they're the ones walking around saying there's no hierarchy!' As such, these experts on horizontality and democratic process (such as the GA) became paradoxical authorities in challenging authority.

In Rancière, this monopoly of knowledge via expertise is considered key to maintaining a cynical power that professes to be egalitarian and yet maintains its own status. This contradiction was also precisely the starting point for his unique political theory after he broke with his teacher - Louis Althusser - during the infamous May 1968 uprisings in France. As a member of the French Communist Party (PCF), 
Althusser also perceived himself to be an expert on the 'science' of socialist emancipation that would overcome the 'ideology' suppressing the 'masses'. As such, he saw the party as the authority that held the truth and knowledge of resistance and subsequently was the measurement of legitimacy for any action. Therefore, when the May '68 strikes happened without the PCF's leadership, the students and workers were automatically categorised and designated as a nonsensical and inauthentic "petty bourgeois' movement by the party.

For Rancière, however, this stance pointed towards a certain contradiction in Althusser's politics: how could he (and the PCF) claim to represent the emancipation of the 'masses', yet not support them when they took action? As such, he concluded that such experts were not only contradicting themselves, but were also cynically maintaining their own hierarchical status and position as prominent and widelyrespected professors or senior party members, despite their supposed support for the overcoming of such hierarchy. This, Rancière remarks, is 'Althusser's Lesson': that history "can only be known or 'made' through the mediation of intellectuals", and that "the 'masses' make history, certainly, but not the masses in general, only the ones we instruct and organise" (Rancière 2011:11).

Therefore, despite one of the main themes of May '68 being precisely "to contend the domain of the expert [and] to disrupt the naturalised spheres of competence (especially the sphere of specialised politics)" (Ross 2002:6), Althusser nevertheless sought to maintain his expert status, and this indicated to Rancière a certain hypocritical position taken by emancipatory experts in general. Indeed, this irony seemed to become even further pronounced when Althusser published his widely read essay on 'Ideological State Apparatus' three years later, pointing out the ideological function of the school (amongst other institutions) in teaching "know-how but in the forms that ensure subjection to the ruling ideology of the mastery of its "practice"" (Althusser 1971:128). For Rancière, this not only demonstrated that Althusser had (ironically) once again missed his own position within these institutions, but also that he was cynically pretending "to discover in the course of his research something that the actions of the masses had already amply demonstrated, but which he advances as a very daring hypothesis: the function of the school as an ideological state apparatus" (Rancière 2011:32). 
Much of Rancière's work since this break with Althusser has, therefore, been an attempt to overcome such a position of paradoxical power, through the assertion of the ability of the philosopher's other - or the 'philosopher's poor' (Rancière 2004) to legitimately speak and appear without them. This has subsequently led him to ideas of radical pedagogy that stem from the work of Joseph Jacotot, who, having gone into exile following the French restoration, found himself attempting to teach in the Netherlands despite knowing no Flemish (and his students knowing no French). After establishing a book as 'something in common', Jacotot found that the students were able to teach themselves and came to the conclusion that theories of unequal intelligence are actually only constructions that serve the status and position of the schoolmaster. As Rancière puts it, "explication is not necessary to remedy an incapacity to understand... on the contrary, this very incapacity provides the structuring fiction of the explicative conception of the world... it is the explicator who needs the incapable and not the other way around; it is he who constitutes the incapable as such" (1991:6). In other words, by asserting the need for explanation in order to foster understanding, the teacher (or 'expert') is able to assert their status as the sole holder of the knowledge that can then be imparted to the student (or 'masses').

Against this, Jacotot (and Rancière) instead argue that all that is really needed for learning is an 'ignorant schoolmaster', who only needs to invest in the student a will to learn (rather than relying on expertise), and who is,

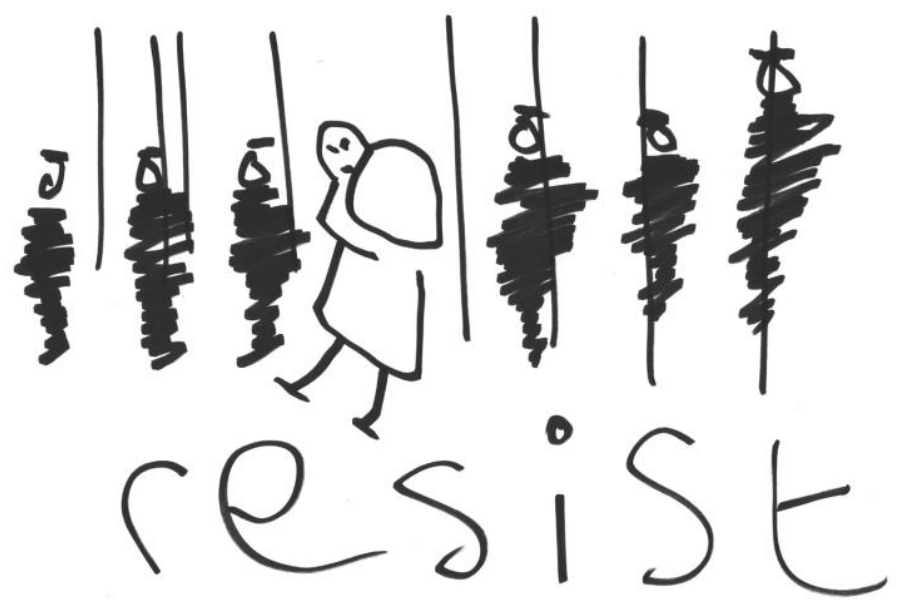
therefore, in principle, able to 'teach' even what they do not know. Furthermore, such a position allows for an 'emancipated student' that "is obliged to use [their] own intelligence" (Rancière 1991:15) without relying on a master to share their expertise. However, it seems that for Occupy (in) London, despite best intentions, this was a position that was ultimately unable to be asserted against the paradoxical power of 
'emancipating expertise'. As A.N.ON puts it, while there is no point in denying that some people have certain useful skills and access to resources...

...what Rancière is talking about is how you allow everyone to be experts and the importance of 'learning to learn'. I mean, are these people who are experts willing to share their knowledge? Instead of Rancière's 'ignorant schoolmaster' I would say that [in Occupy] these were more 'reluctant schoolmasters'

\section{Was Occupy able to presuppose equality?}

Building upon his theory, Rancière argues that expertise can also be even further underlined and justified by the presumption that equality should be an 'end goal'. Such an assertion of equality as a future achievement, he argues, actually presupposes a fundamental inequality in the present, suggesting that there is a disproportionate 'know-how' of how to 'get there' between the student and the teacher that - through educational expertise - will (at some unspecified point) be rectified. In other words, the positing of equality as a future realisation insinuates that the philosopher's other is not currently an equal, but that they can eventually become so through the philosopher's generous expertise. Or, in Rancière's words: “to pose equality as a goal is to hand it over to the pedagogues of progress, who widen endlessly the distance they promise that they will abolish" (2004:223). Against this, therefore, Rancière asks what it would mean to presuppose equality as "not an end to attain, but a point of departure, a supposition to maintain in every circumstance... never would truth speak up for it... never would equality exist except in its verification and at the price of being verified always and everywhere" (1991:138).

Indeed, this was surely what Occupy was intending to do from the start, through their attempt to create a directly democratic horizontal space in which the equality of participants was presupposed. No one was pre-checked or vetted for competence before being able to attend and participate in public general assemblies, working groups or actions, and there was no formal membership process, qualifications or fees required. Instead, this was presupposed to be an inclusive and open space where each, 
in theory, was to be given the equal opportunity to be legitimately heard as rational voice (logos). The aim of Occupy was to precisely allow the "reciprocal recognition of reasonable wills" (Rancière 1991:96) that would constitute an emancipatory space of presupposed equality.

However, it soon became apparent that Occupy's attempt to presuppose equality through the GA model was much more difficult to maintain in the everyday practice of the camps. For instance, not all of the diverse identities that 'joined' the movement were able to adopt an equal subject position, and, even if each were being presupposed as equal, it soon became apparent that those who had positions of 'privilege' (i.e. of 'higher' education; CIS-male; white; able-bodied) were becoming 'more equal than others'. To be clear, this wasn't always and entirely the case, yet there was clearly some bias appearing to stem from pre-existing identity baggage brought in from wider society. As such, structural inequalities were unintentionally re-established (and consistently un-addressed and un-reflected upon) within this allegedly democratic space, and it soon became apparent that "words uttered by some seem to count so much more than words uttered by others" (Hewlett 2007:97).

Therefore, while the equality of intelligence and a capacity to speak was a founding presupposition of the general assembly, this did not mean that the movement was necessarily able to establish and maintain this in practice. As A.N.ON points out, for example, some occupiers simply did not want to put themselves forward and were unwilling to do so:

If you go to a circus and people call you up then some people will be turned off by that - 'this is the worst moment of my life, I've just been called up on stage' - but other people will go: 'oh! I wanted to be pulled up onto the stage and do that!'

...if it's about involvement and you don't want to be involved, then it could be character destructive rather than character building. Its kind of like this 'I'll stand on the stage, because I like singing, and you sit in the audience because you don't like singing'. 
Now, in the Ignorant Schoolmaster, Rancière puts this unwillingness to speak down to a certain arrogance, a lack of will, or a 'false modesty', in which self-contempt is actually contempt for others (1991:79), and, in the case of students, he seems to suggest that they have a tendency to self-marginalise themselves by not taking part and by accepting their allotment as 'incapable' (Rancière 1991:16). Perhaps there is something in this, but through A.N.ON's testimony, as well as my own experience with Occupy (in) London, I find this particular argument somewhat problematic. Not only does Rancière's explanation appear to play down the role of pre-existing structural subject positions that can play an anti-egalitarian role - what I have termed above as 'identity baggage' - but it also seems to go against Rancière's other theory (which I discuss below) on the way that power precisely acts through such a distribution, partition and designating of some subject positions as 'sensible' and others as 'non-sensible'. In other words, there appears to be a slight contradiction in Rancière's argument between the unwillingness of some to participate as being their own 'false modesty', whilst at the same time recognising that some subject positions are pre-positioned as more 'capable' - more audibly and visually 'legitimate' - than others. For example, it may be that a participant in a general assembly decides not to be 'falsely modest' and enact the presupposition of equality by speaking up, yet others still nevertheless discount their words because of their subject positioning as having illegitimate voice. Or, of course, their pre-positioning as illegitimate could simply prevent them from wanting to speak in the first place.

Rancière describes this 'pre-positioning' as 'le partage $d u$ sensible' which comes "from the verb partager, meaning both to share out and to divide up, [and] evokes simultaneously the sharing-out and dividing-up of the sensory" (Davis 2010:91). In other words, subjects are pre-positioned through a distribution, partition or designation of the sensible. By 'sensible', however, I argue that we should (as emancipated students) purposefully manipulate the English translation and take it to mean both what 'appears' (i.e. is perceivable to the senses) and what is 'sensible' (i.e. rational, reasonable, legitimate). This reading is perhaps not Rancière's original intention, but it does have a number of useful effects: emphasising the Kantian underpinnings of the distribution of power through aesthetic judgements; reiterating the distinction between 'rational-sensible' speech (logos) and the designation of animalistic 'noise'; as well as broadening the applicability of the concept by allowing 
the possibility of an 'appearance of non-sense' (something that is unconsidered in the simple binary of legitimacy and appearance versus illegitimacy and non-appearance). Put differently, I argue that by playing on the ambiguity of 'sensible' in English we can fully appreciate the idea of a pre-established partage $d u$ sensible that is, at the same time: an aesthetic policing of what may (or may not) appear sensibly (and sensibly) within a given space; a designation of the legitimacy of some as having authentic 'voice' and others as making simply noise; a partition between those who may reasonably make their grievances known and those that may not.

Furthermore, by playing on this double meaning, we can use this theory to understand how pre-distributed positions of power might have asserted themselves aesthetically within Occupy (with some being still able to 'appear' as 'more sensible' than others), despite intentions to presuppose equality. Indeed, as it became more difficult within the movement to maintain a civil presupposition of equality towards each other under the stresses and tensions of the camps, the identity baggage of prevailing subject positions meant that people soon opted for the easy option of re-conforming to type (thereby losing a certain reflexivity upon these inequalities in the process).

\section{Was Occupy London subjected to an aesthetic policing of what may legitimately appear and what must 'move along'?}

Elaborating on le partage du sensible, Rancière argues that it "consists, before all else, in recalling the obviousness of what there is, or rather of what there is not, and its slogan is: 'Move along! There's nothing to see here!' The police is that which says

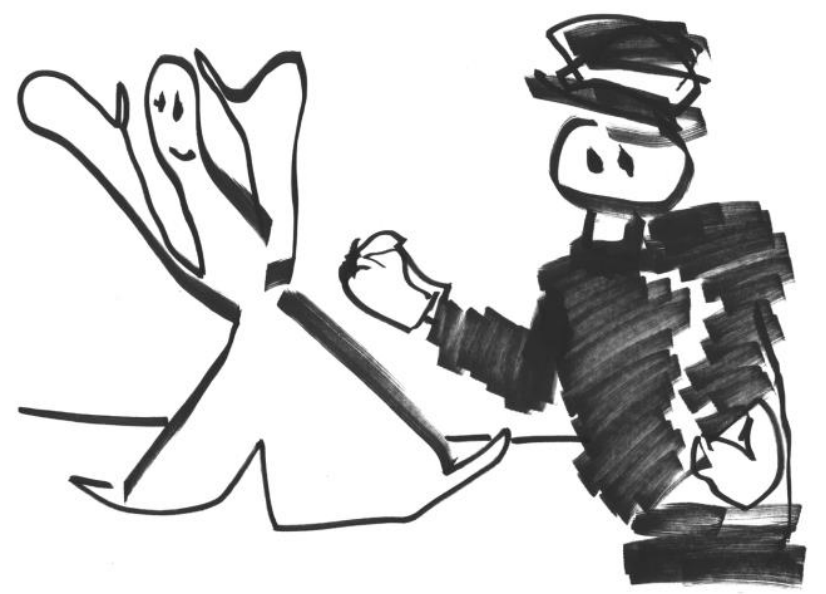
that here, on this street, there's nothing to see and so nothing to do but move along. It asserts that the space for circulating is nothing but the space of circulation" (2010:37). By 'police', therefore, we are supposed not to bring to mind 
only the 'petit' police force that barricade and kettle activists, but also the wider policing of appearance that takes place whenever politicians, the media or public discourse designates a protest as illegitimate non-sense. Therefore, in addition to thinking how subjects were positioned within the movement, we also need to think about the way Occupy was distributed from without: adding another level onto how power ultimately works aesthetically by controlling the designation of authentic, legitimate, rational, reasonable, sensible appearance.

When I asked A.N.ON about this, he gave three examples that he thought demonstrated how those intending to designate the movement as 'non-sense' contested Occupy's insistence on the legitimacy (and 'sensibleness') of their grievances. Firstly, he spoke in terms of his own appearance (which, as I mentioned above, is a permanent aesthetic of ski-goggles, pillowcase head covering and cartoon pyjamas). The police had often used this aesthetic as an excuse to move A.N.ON (and others) along and to deny them a legitimate appearance within the space of protest:

I have my face covered and the cops might come over and say 'you look like you're being offensive' and I say 'well, I've got my doctor's letter so it's not offensive, it's a defence mechanism because I have my medical condition.' This happened at the anti-fracking camp in Balcombe, they're going to say: 'ah, you look like you're doing some direct action with your face covered' and my argument is 'I came up to you two weeks before and asked you to get in touch with my doctor so you know I'm genuine!' So it's chicken and egg because they can always go 'ah, you look offensive' but of course that's the point because they're always going to tell us we're offensive.

The petit-police enact and re-establish the dominant distribution of the sensible by designating A.N.ON's appearance as illegitimate and 'offensive' in that space. On the one hand, one could surely say that this is the very point of activism (to challenge that dominating distribution) but, on the other hand, it also means that the movement's contention can become increasingly tricky to sustain when their appearance in a space is no longer permanent. In other words, as Rancière argues, "that political moment, that moment when those who are not speaking beings somehow speak - this moment is only made possible by the prior production of a space from which such speech can 
appear" (Chambers 2013:120-1) (and I take 'space' here to mean literally a materially persisting space, such as the occupation of urban squares).

As such, the temporary nature of the post-camp Occupy movement has arguably made it more difficult to contest their designation as non-sense. This was suggested by A.N.ON, for instance, by his second example of an attempt to set up a camp on Hampstead Heath that was thwarted by the authorities who argued that, whilst they had no problem with protest, camping was nevertheless prohibited due to health and safety protocols and therefore they had to move along. For A.N.ON, however, this attempt was even further 'moved along' not only by the petit police force and the local council that ultimately decided how people may appear on the heath, but also by the Occupy GA who had begun to emphasise the 'movement' above the 'settlement', prioritising the non-permanent (e.g. meetings and marches or online campaigns) over the maintenance of a physical camp. Or, as he poetically puts it:

The cops of Hampstead would be proud of 'Occupy London TM'. The copse of Hampstead Heath would not.

After the eviction of the St Paul's camp, an aesthetic partition within the movement came about that designated the camps as no longer 'sensible' and created a further hierarchy within Occupy (in) London. Some emphasised the 'hardware' of the camps, whilst others emphasised the 'software' of the movement, and I argue that this was perhaps the most fundamental division within Occupy London. A.N.ON sides firmly with the former and argues for the permanent occupation of physical space as precisely what was important and unique about Occupy in the first place. His third example of the actual eviction at St Paul's demonstrates this:

I remember when we were going to get evicted and we were thinking what to do. One of the ideas I had was to tarp everything. You known you have blue United Nations tents with 'UN' written on them? Well, I said, we should get blue tarp on everything so it's uniform and call it 'United Rations'! So it's telling people what we are: an ideological refugee camp. It's saying that this isn't something you see on the news far away, this is a state of mind. We're not part of this government; we're standing against it. 
Although admitting that this was a particularly 'far-fetched' idea, A.N.ON nevertheless argues for the importance of enforcing a permanent appearance in a space in order to resist the prevailing order of appearances (partage du sensible). In other words, what was potentially radical in Occupy was the attempt to subvert the pre-existing meaning of that space from 'one of circulation' (brokers on their way to work in the stock exchange being materially forced to walk around the camp; churchgoers and tourists prevented from entering the cathedral; the urban mise-enscene re-designed so that the flow of people and capital was re-directed), into a potential space of 'circulating' (idea, politics, alternatives, direct democracy, equality, will, solidarity). Perhaps this radical potential is what was lost after the camps were evicted and the movement became a post-occupation activist network.

\section{Conclusion: Grit and Snow}

The greatest division within the movement was, therefore, between those that emphasised the physical space of the camps, and those who emphasised the ideas, messages and memes of the movement - between the signifiers and the signified. As I have suggested above, it is my contention that the former has more potential in being able to contest the prevailing partage $d u$ sensible because of its material permanence that enforces the appearance of its grievances against those that would 'move it along'. When the pre-existing order attempts to designate the contention as 'nonsense', the material persistence of bodies in space becomes the foremost method of challenging that distribution.

We can also see how this split between the 'settlement' and the 'movement' - the 'hardware' and the 'software'; the 'camps' and the 'meetings', the 'offline' and the 'online' - appeared to play out alongside unequal subject positions: with activist experts shunning the camps whilst the 'ground troops' (often homeless or houseless) had no choice but to stay and continue their commitment to the space. This was described by A.N.ON as akin to the difference between 'grit' and 'snow': 
So they've invited people to build this snowball, thinking 'its going to be a lovely, pure, long-termist, alternative future...it's going to get bigger and we're going to break the banks with it'. But actually, in order to pack it up to begin with, they're looking around thinking there isn't actually much 'snow' so we need to begin with 'the wrong kind of snow' and put that in. Then before long, you look at it, and it's more of a grit-ball than a snowball.

The 'grit' - the homeless and houseless, including newly arrived immigrants; alcoholics and drug addicts; the mentally ill - remained in the physical space of the camps for as long as they were able. Whereas the 'snow' - who, according to A.N.ON were perhaps the more 'middle class' activists - instead thought about issues in advance and had preconceived ideas of what Occupy should (and will) be. As such, they began to adopt positions of expertise and, therefore, began to establish a hierarchy of knowledge and power:

The movers and shakers arrived and the gritty people who held the beach, who packed the snowball early doors with artificial colourings, were outsourced to that country cousin of a protest camp: Occupy Finsbury Square. The GA gave up on the 'overspill' site at Finsbury, but I think Occupy did more there. It was a tougher ride, but you learnt more because you got rid of the system that was at St Paul's.

As such, it is my contention that much can be learnt from Rancière's theory of the ignorant schoolmaster who attempts to avoid and criticise these paradoxical positions of expertise. As I suggested above, this is easier said than done under the pressure of maintaining a resistive space and against the identity baggage that corrupts it. Yet, as A.N.ON suggests, this is surely the only way forward:

Now, what's wrong with talking to grit and allowing the grit to decide what it's going to do? You've got to allow the thing to develop differently and accept that it's a grit ball now, but they wanted it to be a pure system. Some of us thought it was about occupying the space and we thought the people in the GA were helping that - that they were there to support the camps - but they obviously thought differently...You can argue it either way, but the fact is we 
had good will towards each other at the start and it fell apart not least because of their central idea of inviting snow to the streets of London only to find out that 'oh look, there's already grit on the streets!'

In making this argument, however, I do not intend to fetishize or romanticise the camps. Finsbury Square was far from a functioning protest towards the end, resembling something that was far more akin to the damp and muddy carnage of the 'last day at a festival', and struggling to maintain even basic infrastructure for its occupants. What's more, while I don't want to overstate such problems above the numerous achievements of the movement, these spaces were not always able to guarantee the safety of their participants from the public (such as the patrons of local bars who often thought it entertainment to harass and start fights with the protestors), or from each other (including reports of sexual, racist and homophobic harassment). What I do want to argue for, however, is the radical potential of such an occupation of 'public' space over the ephemeral and temporary tactics traditionally used by resistive movements (while nevertheless avoiding ascribing the activists in the camps with some sort of resistive 'purity', as such a move, I think, would only reaffirm partitions and divisions within the movement, and
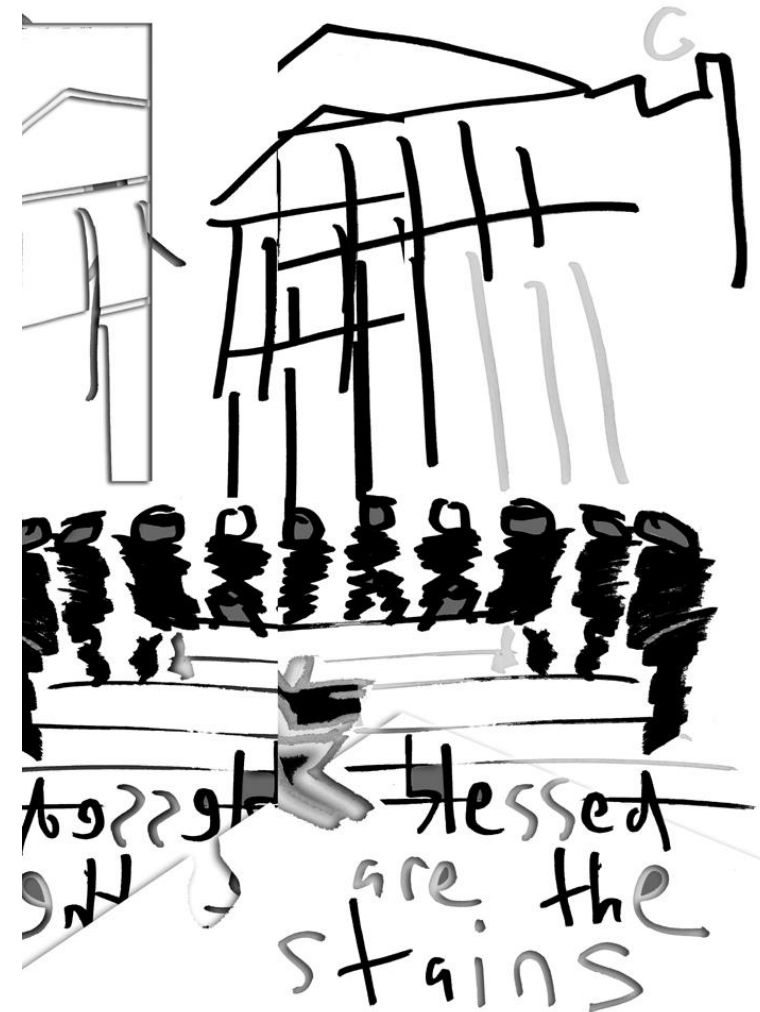
only allow some sort of 'hierarchy of authenticity' that privileges those on the ground).

As I have suggested, divisions between the hardware and the software only enhanced the positions of expertise over the practice and presupposition of equality because, when 'experts' are no longer in the camps, they are able to more easily maintain a distance from those they deem 'non-experts' on the streets, and, even further, become 
those paradoxical (Althusserian) 'authorities on equality.' However, on the other hand, I have also attempted to argue that the problems faced by Occupy (in) London were not necessarily inherent in their attempt to presuppose equality per se, but rather of maintaining this presupposition under the pressures and strains of a tense urban camp environment, in the face of the identity baggage of unequal subject positions, and against the prevailing discourse that attempted to 'move along' the occupiers by denying them a rational, legitimate and sensible appearance. In other words, although I seek to make an argument for both the presupposition of equality and the occupation of physical space, the experience of Occupy nevertheless demonstrated this to be an incredibly difficult and strenuous task.

Overall, this essay has sought to be a non-exhaustive elaboration of some of the ways in which Rancière's theory may be useful to build upon and learn from the Occupy movement in London. Based on one interview, the views expressed here are blatantly limited, but I argue they are nevertheless indicative of some of the themes and issues the movement faced (and continues to face) in bringing about an effective resistance to post-crash (neo)liberal democracy and capitalist financial markets. As a final remark, I also want to emphasise how important it is - whilst making such a critique to adopt neither a position of romantic melancholia or cynicism towards such movements, because such positions already entail a self-fulfilling prophecy (that actually has the effect of forever delaying social change), as well as reproducing unequal subject positions (akin to Rancière's schoolmaster who forever-delays the point of future equality). Instead, it is important to be critical from a position that is somehow 'part' of the movement. Something must be learnt from such resistance, but this must not come from a position of academic expertise or authority: instead it must come from the radical naivety and presupposed equality of an 'ignorant sociologist'. In other words, Rancière's lesson is of "both the right of the ordinary person to be listened to and a celebration of the profound usefulness of learning from what the ordinary person has to say, unmediated as far as possible by the intervention of the more powerful" (Hewlett 2007:86), and this desperately needs to be taken on board in any critical reflection on these movements. 


\section{Acknowledgements}

First thanks must go to A.N.Onymous for his time and for his artwork, as well as the other activists of Occupy London who have given me their time over the course of my $\mathrm{PhD}$ research. I'd also like to thank Simon Dawes for giving me the opportunity to write this article, as well as Nicholas Gane and Finn Obriain for their feedback on earlier drafts.

\section{References}

Althusser, L. (1971) Lenin and Philosophy and Other Essays NLB: London

Bassett, K. (2014) "Rancière, politics, and the Occupy movement" Environment and Planning D: Society and Space 32

Blencowe, C. (2013) "Biopolitical Authority, Objectivity and the Groundwork of Modern Citizenship" Journal of Political Power 6; 1; 9-28

Burgum, S. \& A.N.Onymous (2014) "Samuel Burgum \& A.N.Onymous on Rancière \& Occupy" Theory, Culture and Society Blog

http://theoryculturesociety.org/samuel-burgum-a-n-onymous-on-ranciere-occupy/ Accessed: $24^{\text {th }}$ October 2014

Chambers, S. (2013) The Lessons of Rancière Oxford University Press: Oxford

The Daily Mail (2011) “The thermal images that prove 90\% of tents in the Occupy camp in London are left EMPTY overnight" http://www.dailymail.co.uk/news/article-2053463/Occupy-London-90-tents-StPauls-protest-camp-left-overnight.html Accessed: 18th August 2014

Davis, O. (2010) Jacques Rancière Polity Press: Cambridge

Hewlett, N. (2007) Badiou, Balibar, Rancière Continuum: London

Lorey, I. (2014) "The 2011 Occupy Movements: Rancière and the Crisis of Democracy" Theory, Culture and Society 25.7-8

Pretoulis, M. \& Thomassen, L. (2013) "Political Theory in the Square: Protest, Representation and Subjectification" Contemporary Political Theory 12; 3; 166184

Rancière, J. (1991) The Ignorant Schoolmaster: Five Lessons in Intellectual Emancipation Stanford University Press: California 
Rancière, J. (2004) The Philosopher and His Poor Duke University Press: Durham

Rancière, J. (2010) Dissensus: On Politics and Aesthetics Continuum: London

Rancière, J. (2011) Althusser's Lesson Continuum: London

Raunig, G. (2014) "Singers, Cynics, Molecular Mice: The Political Aesthetics of Contemporary Activism" Theory, Culture and Society 25.7-8

Ross, K. (2002) May '68 and its Afterlives University of Chicago Press: Chicago

Sinha, S. \& Back, L. (2013) "Making Methods Sociable: Dialogue, Ethics and Authorship in Qualitative Research" Qualitative Research [Online First]

Tumblr (2014) "We are the 99\%" http://wearethe99percent.tumblr.com Accessed: $2^{\text {nd }}$ November 2014

Winlow, S. (2012) 'Is It Ok To Talk About Capitalism Again?' in S. Winlow \& R. Atkinson (eds) New Directions in Crime and Deviance Routledge: London

Sam Burgum is a $\mathrm{PhD}$ candidate in Sociology at the University of Warwick and has been conducting research with Occupy London since 2012. You can follow Sam on Twitter (@sjburgum) or visit his blog (esjaybe.wordpress.net).

Email: s.j.burgum@warwick.ac.uk 